\title{
Comportamento da Taxa de Câmbio no Brasil: Uma Análise a partir da Paridade Descoberta da Taxa de Juros
}

\section{Exchange Rate Behavior in Brazil: An Analysis from the Uncovered Interest Parity}

Guilherme Ricardo dos Santos Souza e Silva* Marcelo Curado**

Resumo: O objetivo central deste artigo é analisar o comportamento da taxa de câmbio no Brasil e sua relação com a taxa de juros. O modelo adotado para analisar a relação entre as variáveis é uma adaptação da paridade descoberta da taxa de juros. Os resultados obtidos, para o período compreendido entre janeiro de 2003 e março de 2008, sugerem que a variação cambial defasada e a variação do prêmio de risco foram os principais determinantes das flutuações na taxa de câmbio. Dessa forma, a política monetária teria menor influência no período considerado pelo estudo. A influência do prêmio de risco indica a relevância da situação internacional e das variáveis macroeconômicas para o entendimento das variações cambiais.

Palavras-chave: Taxa de câmbio. Paridade descoberta da taxa de juros. Risco-país.

Abstract: The aim of this paper is to analyze the behavior of the exchange rate in Brazil and its relation to the interest rate. The model used to analyze the relationship between the variables is an adaptation of the uncovered interest parity. The results for the period between January 2003 and March 2008, suggest that the exchange rate and the lagged change in the risk premium were the main determinants of exchange rate fluctuations. Thus, monetary policy would have less influence in the period considered by the study. The influence of the risk premium indicates the relevance of the international situation and the macroeconomic variables to the understanding of exchange rate changes.

Keywords: Exchange rate. Uncovered interest parity. Country-risk.

\footnotetext{
* Doutorando no Programa de Pós-Graduação em Desenvolvimento Econômico da Universidade Federal do Paraná (UFPR). Professor do Setor de Educação Profissional e Tecnológica da UFPR. E-mail: guilherme.ricardo@ufpr.br

** Doutor em Política Econômica pela Universidade Estadual de Campinas (Unicamp). Professor do Programa de Pós-Graduação em Desenvolvimento Econômico da UFPR. Pesquisador do Programa "Cátedras para o Desenvolvimento" do Instituto de Pesquisa Econômica Aplicada (Ipea). E-mail: curado@ufpr.br
} 


\section{1 lntrodução}

A conjuntura internacional da última década evidenciou a importância da taxa de câmbio no processo de crescimento de um amplo conjunto de economias emergentes. A literatura econômica de inspiração keynesiana sobre a sua relevância para o funcionamento do sistema econômico é ampla. Eichengreen (2004), Edwards (2006) e Bresser-Pereira (2007), entre outros, têm advogado em favor da importância da taxa de câmbio sobre o comportamento do saldo comercial, da taxa inflação e da taxa de crescimento da economia. Edwards (2006, p. 28), por exemplo, afirma que: "The exchange rate is one of most important macroeconomic variables in the emerging and transition countries. It affects inflation, exports, imports and economic activity".

O papel exercido pela taxa de juros na determinação da taxa de câmbio é um dos principais temas deste debate. $\mathrm{O}$ argumento básico é que, tudo o mais constante, quanto maior o diferencial existente entre a taxa de juros doméstica e a taxa internacional, maior a rentabilidade dos ativos que rendem juros desta economia. A existência de um diferencial positivo de juros contribuiria, dessa forma, para elevar a entrada de capitais de curto prazo, o que, num regime de flutuação cambial, implicaria uma pressão para valorização da moeda doméstica. Assim, para uma dada taxa de juros internacional, a realização de uma política monetária contracionista, tudo o mais constante, contribuiria para promover a valorização da moeda doméstica. ${ }^{1}$ Bresser-Pereira (2007), entre outros, argumenta que o caráter contracionista da política monetária brasileira, particularmente entre 2003 e 2007, foi um elemento fundamental para explicar a valorização do real no período.

Este trabalho pretende contribuir para o debate sobre o comportamento da taxa de câmbio no Brasil e, em especial, sua relação com a taxa de juros através da elaboração de um estudo econométrico. ${ }^{2}$ Para tanto, é estimada uma versão da paridade descoberta da taxa de juros a partir da metodologia de vetores autorregressivos (VAR). Através da análise das funções impulso-resposta, são avaliados os efeitos sobre a taxa de câmbio de choques nas variáveis que a determinam, de acordo com o modelo selecionado. Adicionalmente, a análise da decomposição da variância apresenta o poder explicativo dos fatores considerados em relação às variações cambiais no período analisado.

O trabalho encontra-se organizado da seguinte forma. Após esta breve introdução, a seção 2 apresenta o referencial teórico utilizado, ou seja, apresenta a

$1 \quad$ A análise supõe evidentemente a existência de algum grau de mobilidade nos fluxos de capital.

2 O estudo é realizado para o período compreendido entre janeiro de 2003 e março de 2008. Para uma discussão sobre a escolha do período de análise, veja-se a seção 3.2. 
discussão sobre o significado da paridade descoberta da taxa de juros. A seção 3 apresenta os resultados do estudo empírico realizado. Finalmente, a seção 4 apresenta as considerações finais do trabalho.

\section{Referencial Teórico}

A literatura sobre a determinação da taxa de câmbio numa economia aberta é vasta. ${ }^{3}$ Este trabalho não pretende contribuir para esse debate teórico. Seu objetivo é substancialmente mais restrito. Pretende-se apenas analisar a evolução da taxa de câmbio no Brasil e em especial sua relação com o diferencial de juros. Tendo em vista esse objetivo, optou-se pela escolha do modelo de paridade descoberta da taxa de juros como referencial teórico para definição da relação entre as variáveis câmbio e juros. A escolha se justifica por diversos motivos, entre eles: 1) a paridade descoberta de taxa de juros é um modelo amplamente aceito pela literatura econômica para análise das relações entre as variáveis selecionadas; e 2) o Banco Central do Brasil, em seu modelo de previsão de inflação utiliza, desde a adoção do regime de metas de inflação, a paridade descoberta da taxa de juros para determinar a relação entre as variáveis câmbio e juros. ${ }^{4}$

A seção 2.1 apresenta uma breve discussão sobre o conceito de paridade coberta da taxa de juros (CIP), ponto de partida para a análise da seção 2.2 que discute, sucintamente, o conceito de paridade descoberta de taxa de juros (UIP).

\subsection{Paridade Coberta da Taxa de Juros (CIP)}

A paridade da taxa de juros (CIP) foi inicialmente apresentada por Keynes (1923) e pode ser entendida como a identidade que relaciona a taxa de juros com a taxa de câmbio. De acordo com essa teoria, o retorno nominal de um título em um país deve ser igual ao de outro país quando ambos os retornos são medidos na mesma moeda (FISHER, 1930).

Segundo Frankel (1979), a paridade da taxa de juros está associada com mercados eficientes nos quais os títulos de diferentes países são substitutos perfeitos, sendo válida a seguinte relação:

$$
d=i-i^{*}
$$

onde: $i$ é definido como o logaritmo de um mais a taxa doméstica de juros e $i^{*}$ é definido como o logaritmo de um mais a taxa internacional de juros. Se $d$ é consi-

3 Para uma apresentação dos principais modelos que trabalham com o tema, veja-se, entre outros, Obstfeld e Rogoff (1996).

4 Para uma apresentação do modelo de previsão da inflação do Banco Central do Brasil no regime de metas de inflação, sugere-se a leitura de Bogdanski, Tombini e Werlang (2000). 
derada a taxa de desconto futura, ${ }^{5}$ então (1) é a relação que implica a denominada paridade coberta da taxa de juros (CIP - Covered Interest Parity).

Se considerarmos o caso de perfeita mobilidade de capitais, isto é, na ausência de controles de capitais e custos de transação, a paridade coberta da taxa de juros deve ser válida com exatidão, uma vez que a sua falha implicaria oportunidades de ganhos de arbitragem sem risco. Expandindo a equação (1) e definindo $d$ como a taxa de desconto futura, temos:

$$
d=e_{f}-e_{s}=i-i^{*}
$$

Dessa forma, podemos escrever (3):

$$
i=i^{*}+e_{f}-e_{s}
$$

onde $e_{f}$ é o logaritmo da taxa futura de câmbio no mercado a termo e $e_{s}$ é o logaritmo da taxa de câmbio à vista (spot).

\subsection{Paridade Descoberta da Taxa de Juros (UIP)}

A paridade descoberta da taxa de juros (UIP - Uncovered Interest Parity) também parte da equação (1), porém agora definindo $d$ como a taxa esperada de depreciação da moeda doméstica. Segundo Frankel (1979), se considerarmos um ambiente sem incerteza, como em uma economia com previsibilidade perfeita (perfect foresight), então a taxa de desconto futura seria igual à taxa esperada de depreciação da moeda.

No entanto, em uma economia onde existe incerteza e os participantes do mercado são avessos ao risco, a taxa de desconto futura pode ser diferente da taxa esperada de depreciação da moeda. Então, partindo da equação (1), temos:

$$
d=E_{t} e_{t+1}-e_{t}=i_{t}-i_{t} *
$$

onde $E_{t}$ (.) é a expectativa condicional às informações disponíveis em $t, e_{t+1}$ é o logaritmo da taxa de câmbio à vista $(e m t+1)$ e $e_{t}$ é o logaritmo da taxa de câmbio à vista $(\mathrm{em} t)$.

A equação (4), que representa a paridade descoberta da taxa de juros, considera a hipótese de que os ativos dos diferentes países são substitutos perfeitos. Se relaxarmos essa hipótese, é necessária a consideração de que existe um prêmio de risco. Hooper e Morton (1982) consideram o caso em que a substituição entre os ativos de diferentes países é imperfeita e, portanto, é necessária a adição de um prêmio de risco à equação (4):

5 A taxa de desconto futura é definida como o logaritmo da taxa futura de câmbio (no mercado a termo) menos o logaritmo da taxa de câmbio à vista (spot).

6 A taxa esperada de depreciação da moeda d,é dada por:

$d=\ln \left(\frac{E_{t} s_{t+1}}{s_{t}}\right)=\ln \left(E_{t} s_{t+1}\right)-\ln \left(s_{t}\right)=E_{t} e_{t+1}-e_{t}$ 


$$
E_{t}\left[e_{t+1}\right]-e_{t}=i_{t}-i_{t} *-x_{t}
$$

onde $x_{t}$ é o prêmio de risco que os detentores de ativos exigem sobre os ativos denominados em moeda doméstica relativamente aos ativos denominados em moeda estrangeira, dadas as riquezas existentes, estoques de ativos e taxas de retornos relativas esperadas para esses ativos.

Dooley e Isard (1979) mostraram que o modelo de balanço de portfolio pode ser solucionado para o prêmio de risco. Na forma reduzida, o modelo expressa o prêmio de risco como uma função de diversos fatores, além das taxas relativas esperadas de retorno, que determinam a oferta e a distribuição de ativos externos. Esses fatores incluem os déficits orçamentários do setor público, saldos em contas correntes e intervenções oficiais no mercado de câmbio.

Neste trabalho consideraremos que o prêmio de risco da equação (5), $x_{t}$, será o denominado risco-país. Segundo o Banco Central do Brasil, ${ }^{8}$ o risco-país ou risco-Brasil é um indicador que busca expressar objetivamente o risco a que os investidores internacionais estão sujeitos quando investem no país. No mercado internacional, o indicador mais utilizado desse risco é uma medida da média do retorno de uma carteira hipotética composta por títulos emitidos pelo Brasil no exterior, em relação ao retorno dos títulos do tesouro norte-americano com maturidade compatível (considerados livres de risco). Neste artigo será utilizado o índice EMBI+ Brazil, calculado pelo JP Morgan, como medida do risco-país.

\section{Análise Empírica}

Nesta seção será apresentado o desenvolvimento do modelo para a determinação das variações cambiais; a execução dos testes econométricos e os resultados obtidos com o exercício. Conforme mencionado na introdução, o exercício econométrico tem o objetivo principal de avaliar o peso dos fatores explicativos das variações cambiais, assunto que gerou um intenso debate econômico, especialmente a partir do final do ano de 2003.

Para avaliar a questão, apresenta-se o exercício baseado no modelo adaptado da paridade descoberta da taxa de juros, que considera a variação do diferencial de juros e a variação do risco-país como os principais determinantes das variações cambiais.

\subsection{Modelo}

A base teórica do modelo é a paridade descoberta da taxa de juros. Considerando a equação (5) apresentada anteriormente, temos:

7 O prêmio de risco também costuma ser representado pela letra $\phi$..

8 Publicação do Banco Central do Brasil, Frequently Asked Questions Series, Country Risk, agosto de 2005. 


$$
E_{t}\left[e_{t+1}\right]-e_{t}=i_{t}-i_{t} *-x_{t}
$$

onde: $E_{t}\left[e_{t+1}\right]$ é o valor esperado do logaritmo da taxa de câmbio em $\mathrm{t}+1 ; e_{t}$ é o logaritmo da taxa de câmbio em $t ; i_{t}$ é o logaritmo de um mais a taxa de juros doméstica; $i_{t}^{*}$ é o logaritmo de um mais a taxa de juros internacional; e $x_{t}$ é o risco-país.

Para testar o modelo empiricamente, é necessária uma definição a respeito de como são formadas as expectativas em relação à taxa de câmbio a vigorar no próximo período $E_{t}\left[e_{t+1}\right]$. Uma alternativa proposta por Dornbusch (1976) supõe que a depreciação esperada da taxa de câmbio é proporcional à discrepância entre a taxa de câmbio de longo prazo e a taxa de câmbio à vista corrente.

Obviamente, nesse caso, é necessária a distinção entre a taxa de câmbio de longo-prazo, para a qual a economia finalmente convergirá, e a taxa de câmbio à vista (spot) corrente. Dornbusch mostra que esse processo de formação de expectativa é consistente com previsão perfeita. Essa proposta, porém, apresenta o inconveniente da necessidade de se determinar a taxa de câmbio de equilíbrio de longo prazo da economia, assunto em geral bastante controverso.

Uma alternativa, utilizada por Bogdanski et al. ${ }^{9}$ (2000) no trabalho que orienta a implementação do sistema de metas de inflação pelo Banco Central do Brasil, supõe apenas como as expectativas se modificam ao longo do tempo, sem a necessidade de se determinar o valor efetivo da taxa de câmbio esperada no próximo período. Essa abordagem é denominada modelo RWMS, isto é, Random Walk with Monetary Surprise, que relaciona os movimentos na taxa de câmbio nominal a movimentos nos diferenciais de juros ajustados pelo prêmio de risco. $\mathrm{O}$ modelo parte da hipótese de que as mudanças nas expectativas da taxa de câmbio seguem um white noise process, isto é:

$$
E_{t}\left[e_{t+1}\right]-E_{t-1}\left[e_{t}\right]=\eta_{t}
$$

Tirando a primeira diferença da equação (5), temos:

$$
\left(E_{t} e_{t+1}-E_{t-1} e_{t}\right)-\left(e_{t}-e_{t-1}\right)=\Delta i_{t}-\Delta i_{t}^{*}-\Delta x_{t}
$$

Substituindo a equação (6) na equação (7), temos:

$$
\begin{gathered}
\eta_{t}-\Delta e_{t}=\Delta i_{t}-\Delta i_{t}^{*}-\Delta x_{t} \\
\text { ou } \\
\Delta e_{t}=\Delta x_{t}-\Delta\left(i_{t}-i_{t}^{*}\right)+\eta_{t}
\end{gathered}
$$

A equação (8) mostra que a variação na taxa de câmbio nominal é função da variação no prêmio de risco e da variação no diferencial entre os juros domésticos os juros internacionais, mais o termo de erro. Esse resultado, conforme destacado

$9 \quad$ O trabalho de Bogdanski et al. (2000) faz parte do working paper series do Banco Central do Brasil.

10 Esta hipótese significa que não ocorrerão maiores perturbações na taxa de câmbio esperada para o próximo período. Um white noise apresenta média zero e variância constante. 
por Muinhos et al. (2001), é um pouco diferente do apresentado pela tradicional paridade descoberta da taxa de juros. O modelo da equação (8), apesar de incorporar algumas hipóteses fortes, apresenta duas características desejáveis:

a) nesta especificação não há necessidade da elaboração de hipóteses a respeito de taxas de câmbio futuras;

b) combina a hipótese de random walk com a característica desejável de que as taxas de câmbio são sensíveis à variações nos diferenciais de taxas de juros.

Assim, o modelo econométrico considerando os coeficientes desconhecidos é expresso pela equação (9):

$$
\Delta e_{t}=\alpha_{1} \Delta x_{t}+\alpha_{2} \Delta\left(i_{t}-i_{t}^{*}\right)+\eta_{t}
$$

\subsection{Base de Dados}

Os dados utilizados na análise empírica foram extraídos do Banco Central do Brasil, da base de dados do Fundo Monetário Internacional - FMI (International Financial Statistics - IFS) e do JP Morgan. Os dados têm periodicidade mensal e abrangem o período de janeiro de 2003 a março de 2008.

A justificativa para a escolha do período analisado é a seguinte. O período anterior, particularmente o ano de 2002, foi marcado por profundas incertezas na economia brasileira, particularmente associadas ao processo eleitoral, que acabaram provocando alterações profundas no mercado de câmbio. De fato, entre janeiro e outubro de 2002, a taxa de câmbio nominal apresentou uma variação de $60 \%,{ }^{11}$ fortemente influenciada pelas incertezas anteriormente descritas, que não são objeto de estudo deste trabalho e que poderiam contaminar os dados para a análise que se pretende realizar.

Por outro lado, a partir de 2008, o comportamento das variáveis juros e câmbio passa a refletir os efeitos da crise financeira global, "iniciada" em setembro de 2008 com o pedido de concordata do banco de investimentos norte-americano Lehman Brothers. ${ }^{12}$ Entre setembro de 2008 e março de 2009, a variação na taxa de câmbio nominal chegou a $44 \%$, novamente influenciada por fatores que não pretendemos explicar nesta análise. Em outras palavras, o período contido entre janeiro de 2003 e março de 2008 foi escolhido para análise com intuito de evitar momentos nos quais as relações entre as variáveis câmbio e juros foram profundamente afetadas por fenômenos exógenos.

11 Dados do Banco Central do Brasil. Taxa de câmbio nominal média (compra - série 3.697).

12 Considera-se apenas para fins de simplificação o início da crise a partir do pedido de concordata do Banco Lehman Brothers, visto que o processo de crise financeira tem um começo indeterminado e gradual. 
As séries avaliadas no estudo econométrico foram as seguintes: taxa de câmbio nominal, taxa de juros doméstica, taxa de juros internacional e risco-país.

Com relação à taxa de câmbio nominal, foi escolhido o preço médio de compra do dólar estadunidense ao longo do mês, medido em R $\$ /$ US\$. A série correspondente é a de número 3.697 do Bacen.

Para a avaliação da variável taxa de juros doméstica foi escolhida a taxa Selic (Sistema Especial de Liquidação e Custódia) acumulada no mês, anualizada (em $\%)$, correspondente à série número 4.189 do Bacen.

Com relação à variável taxa de juros internacional, foi utilizada a taxa de juros dos fundos federais do tesouro norte-americano (\% ao ano). Essa variável foi escolhida como proxy da taxa de juros internacional, uma vez que os títulos dos fundos federais norte-americanos são considerados de baixo risco e representam a principal alternativa para os investidores internacionais em relação às outras oportunidades de investimento. Os dados foram obtidos do FMI (International Financial Statistics).

Finalmente a medida do prêmio de risco utilizada, conforme discutido na seção 2.2, foi o índice EMBI+ Brazil medido em pontos base pelo JP Morgan. O EMBI+ é construído como uma composição dos seguintes instrumentos de dívida para os países emergentes: Bradies, eurobonds e traded loans emitidos pelo governo soberano.

\subsection{Aplicação dos Testes no Modelo UIP Adaptado}

Nesta seção serão apresentados os testes econométricos realizados e os resultados obtidos.

Conforme demonstrado na seção 3.1, a variação da taxa de câmbio a partir da paridade descoberta da taxa de juros pode ser escrita da seguinte forma:

$$
\Delta e_{t}=\Delta x_{t}-\Delta\left(i_{t}-i_{t}^{*}\right)+\eta_{t}
$$

ou considerando os coeficientes desconhecidos para o modelo econométrico:

$$
\Delta e_{t}=\alpha_{1} \Delta x_{t}+\alpha_{2} \Delta\left(i_{t}-i_{t}^{*}\right)+\eta_{t}
$$

O Gráfico 1 apresenta o comportamento histórico das séries consideradas nesse modelo. 
Gráfico 1 - Variação do câmbio nominal, diferencial de juros e risco-país

DELTA_CAMBIO_NOMINAL

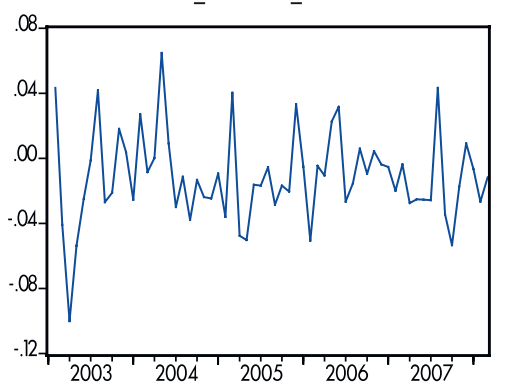

DELTA_RISCO

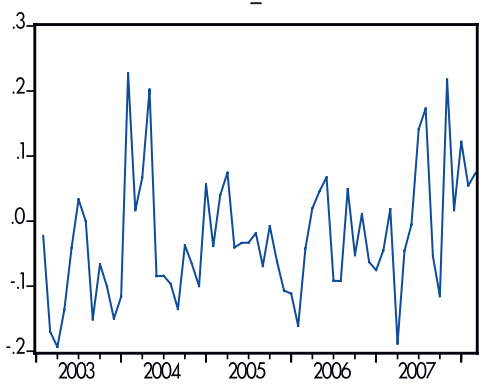

DELTA_DIFERENCIAL_JUROS

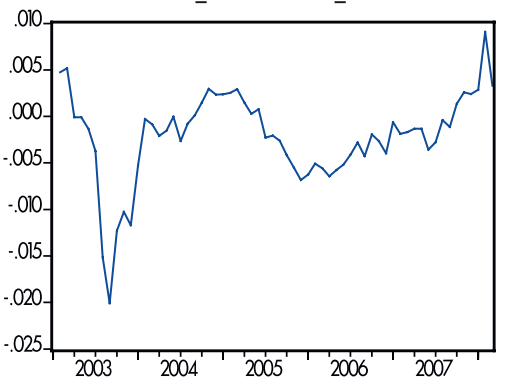

Fonte: Elaboração própria a partir do software e-views 6.0.

\subsubsection{Avaliação da estacionariedade das séries}

A primeira etapa para a elaboração do estudo econométrico é a avaliação da estacionariedade das séries do modelo. Para essa avaliação foi realizado o teste ADF (Augmented Dickey-Fuller) que testa a hipótese nula de presença de raiz unitária na série temporal. De acordo com o modelo definido pela equação (9), as variáveis avaliadas pelo teste $\mathrm{ADF}$ foram: variação da taxa de câmbio nominal, variação do risco-país e variação do diferencial entre a taxa de juros doméstica e internacional. ${ }^{13}$ Os resultados obtidos são apresentados na Tabela 1.

Tabela 1 - Teste de raiz unitária (Adf) - Modelo UIP adaptado

\begin{tabular}{lccccc}
\hline Variável & Defasagens & Tendência & Intercepto & ADF & Valor Crítico 5\% \\
\hline $\begin{array}{l}\text { Delta_Cambio_ } \\
\text { Nominal }\end{array}$ & 0 & Não & Sim & $-7.128^{*}$ & $-2,910$ \\
$\begin{array}{l}\text { Delta_Risco } \\
\begin{array}{l}\text { Delta_Diferen- } \\
\text { cial_Juros }\end{array}\end{array}$ & 0 & Não & Não & $-5,522^{*}$ & $-1,946$ \\
\hline
\end{tabular}

Fonte: Elaboração própria a partir do software E-views 6.0.

Nota: * Significativo a 1\%; * Significativo a 5\%.

Os resultados dos testes de raiz unitária sinalizam que as três séries avaliadas são estacionárias em nível, a 5\% de significância. ${ }^{14}$

\subsubsection{O Modelo VAR}

Um ponto importante na definição do VAR é a escolha do número de defasagens a serem consideradas no modelo. A Tabela 4 apresenta os resultados dos

13 Para a realização dos testes foram utilizados os logaritmos neperianos das três variáveis do modelo em questão, conforme o desenvolvimento da seção 3.1.

14 Cabe salientar que as séries observadas são as variações (primeira diferença) das séries de câmbio nominal, risco-país e diferencial de juros em nível, uma vez que o modelo teórico assim as considera. Dessa forma, outra interpretação possível seria a de que as variáveis originais (em nível) são estacionárias em primeira diferença. 
critérios para seleção de defasagens aplicados sobre as séries em estudo. Os critérios de seleção apresentam diferentes sugestões de defasagens para o modelo VAR. Os critérios de Schwarz e Hannan-Quinn selecionaram o modelo com uma defasagem. O critério de informação de Akaike, Final Prediction Error e LR selecionaram o modelo com cinco defasagens. Optou-se por trabalhar com o modelo VAR de uma defasagem para a continuidade do exercício econométrico. Cabe salientar que esse modelo não apresenta o problema de autocorrelação serial dos resíduos. ${ }^{15}$

Tabela 2 - Critério de seleção de defasagem do VAR - Modelo UIP adaptado

\begin{tabular}{ccccccc}
\hline Lag & LogL & LR & FPE & AIC & SC & HQ \\
\hline 0 & 423,219 & NA & $7.93 \mathrm{e}-11$ & $-14,7445$ & $-14,6370$ & $-14,7028$ \\
1 & 460,2735 & 68,90755 & $2.96 \mathrm{e}-11$ & $-15,7289$ & $-15,29878^{*}$ & $-15,56174^{*}$ \\
2 & 467,9261 & 13,42569 & $3.12 \mathrm{e}-11$ & $-15,6816$ & $-14,9289$ & $-15,3891$ \\
3 & 469,7937 & 3,07987 & $4.03 \mathrm{e}-11$ & $-15,4314$ & $-14,3561$ & $-15,0135$ \\
4 & 482,6585 & 19,86143 & $3.57 \mathrm{e}-11$ & $-15,5670$ & $-14,1691$ & $-15,0237$ \\
5 & 501,4852 & $27,08409^{*}$ & $2.58 \mathrm{e}-11^{*}$ & $-15,91176^{*}$ & $-14,1913$ & $-15,2431$ \\
\hline
\end{tabular}

Fonte: Elaboração própria a partir do software E-views 6.0.

Nota: * Indica a ordem de defasagem selecionada pelo modelo.

Devido à dificuldade em se interpretar os coeficientes estimados para o modelo VAR, é usual avaliar os resultados por meio da função impulso-resposta e da decomposição da variância (innovating accounting). É importante lembrar que as inferências obtidas através da análise da função impulso-resposta e da decomposição da variância se mostram extremamente sensíveis à ordenação das variáveis no VAR.

Em função disso, foi utilizado o teste Granger Causality/Block Exogeneity Wald para definir um ordenamento estatisticamente consistente das variáveis no VAR. O teste Granger Causality/Block Exogeneity Wald calcula a significância conjunta de cada variável endógena defasada para cada equação do VAR. Além disso, o teste também fornece a significância conjunta de todas as variáveis endógenas defasadas na equação. Os resultados do teste realizado são apresentados na Tabela 3.

15 Através do Teste LM testou-se a hipótese nula de não correlação serial. Estimando o modelo com uma defasagem, a estatística LM, a 5\% de significância, assume valor de 15,62 (Prob = 0,0753) o que resulta na impossibilidade de rejeição da hipótese nula de não correlação serial dos resíduos. 
Tabela 3 - Teste Granger Causality/Block Exogeneity Wald - Modelo UIP adaptado

\begin{tabular}{lcccccc} 
& \multicolumn{5}{c}{ Variável Dependente } \\
\cline { 2 - 7 } & \multicolumn{2}{c}{$\begin{array}{c}\text { Delta_Cambio_No- } \\
\text { minal }\end{array}$} & \multicolumn{2}{c}{ Delta_Risco } & \multicolumn{2}{c}{ Delta_Diferencial } \\
& Chi-Sq & Prob & Chi-Sq & Prob & Chi-Sq & Prob \\
\cline { 2 - 7 } & & & 5,21 & 0,02 & 0,74 & 0,39 \\
\hline $\begin{array}{l}\text { Delta_Cambio_No- } \\
\text { minal }\end{array}$ & 8,64 & 0,003 & & & 0,18 & 0,67 \\
$\begin{array}{l}\text { Delta_Risco } \\
\begin{array}{l}\text { Delta_Diferen- } \\
\text { cial_Juros }\end{array}\end{array}$ & 7,90 & 0,005 & 0,11 & 0,73 & & \\
\hline Total & $\mathbf{1 1 , 9 7}$ & $\mathbf{0 , 0 0 3}$ & $\mathbf{6 , 6 9}$ & $\mathbf{0 , 0 4}$ & $\mathbf{0 , 7 5}$ & $\mathbf{0 , 6 9}$ \\
\hline
\end{tabular}

Fonte: Elaboração própria a partir do software E-views 6.0.

Nota: O total representa apenas a soma da estatística qui-quadrado, não a soma das probabilidades.

O teste demonstra, a partir da estatística qui-quadrado, que a taxa de câmbio nominal é a variável "mais endógena" do modelo, seguida pelo risco-país e por último pelo diferencial de juros. Para a ordenação das variáveis no modelo VAR, parte-se da variável mais exógena para a mais endógena, de forma que temos a seguinte ordenação: variação do diferencial de juros, variação do risco-país e variação da taxa de câmbio nominal.

Isso significa que, no modelo, a variação no diferencial de juros não responde contemporaneamente às inovações nas outras duas variáveis. Por outro lado, a variável de maior interesse em nosso estudo, a variação cambial, por ser a variável mais endógena, é afetada logo no primeiro período por inovações nas demais variáveis. Esse resultado é bastante desejável, uma vez que o objetivo principal do exercício é verificar como a taxa de câmbio nominal se comporta quando temos variações nas outras variáveis de interesse, e assim é possível a avaliação dos impactos logo a partir do primeiro período.

O Gráfico 2 apresenta as funções impulso-resposta da taxa de câmbio às inovações de um desvio padrão na própria taxa de câmbio, no risco-país e no diferencial entre a taxa de juros doméstica e internacional. De acordo com Enders (2004), as funções impulso-resposta mostram os efeitos de longo prazo nas séries temporais quando há um determinado choque exógeno em alguma das variáveis endógenas do modelo. As linhas contínuas representam as funções impulsoresposta, enquanto as linhas pontilhadas representam os intervalos de confiança de dois desvios padrão. São analisados os impactos ocorridos até um período de dez meses após os choques. A análise da função impulso-resposta é particularmente útil para a observação da direção, do tempo de duração e do padrão 
de reação da resposta da variável de interesse a impulsos de um desvio padrão contemporâneos e futuros nas variáveis endógenas do modelo.

O primeiro gráfico apresenta a resposta da variação da taxa de câmbio nominal a um choque nela mesma. Observa-se que o choque produz uma resposta de intensidade relativamente alta, porém de curta duração, cessando o impacto a partir do quarto período após a inovação. Intuitivamente, podemos interpretar esse resultado considerando que os agentes econômicos tendem, no curto prazo, a elevar suas expectativas em relação ao preço futuro do dólar quando há uma apreciação no valor corrente da moeda americana. Esse comportamento é bastante comum entre as variáveis econômicas, ainda em especial para aquelas que possuem um forte componente expectacional, como é o caso da taxa de câmbio.

O segundo gráfico mostra a resposta da variação da taxa de câmbio nominal a um choque na variação do risco-país. Verifica-se que o choque, tal como no caso acima, produz uma resposta de intensidade relativamente elevada e também de curta duração, praticamente cessando o efeito a partir do terceiro período após a inovação. Esse resultado pode ser interpretando intuitivamente, considerando que o aumento do risco-país, em pontos-base, tende a afugentar os capitais estrangeiros de curto-prazo investidos em títulos domésticos, aumentando imediatamente a demanda por dólares para remessas ao exterior.

O último gráfico apresenta a resposta da variação da taxa de câmbio nominal a um choque na variação do diferencial de juros. Observa-se que o choque, nesse caso, causa uma resposta de menor intensidade sobre a variação cambial. Entretanto, é interessante notar que a duração do efeito é maior que nos casos anteriores, cessando praticamente apenas no décimo período após a inovação (apesar de apresentar tendência decrescente após o segundo período). 
Gráfico 2 - Função impulso-resposta do câmbio - Modelo UIP adaptado Response to Cholesky One S.D. Innovations \pm 2 S.E.

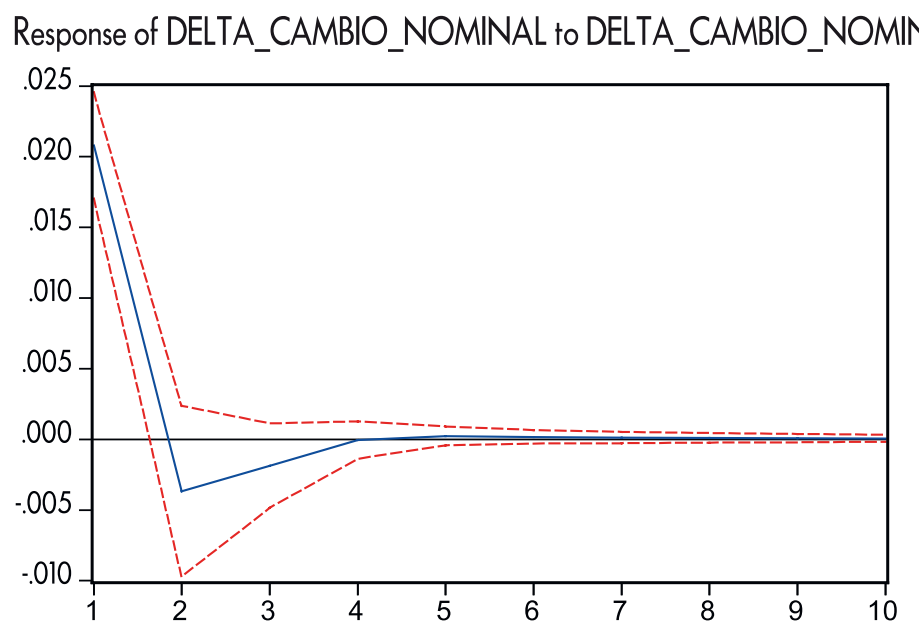

Response of DELTA_CAMBIO_NOMINAL to DELTA_RISCO

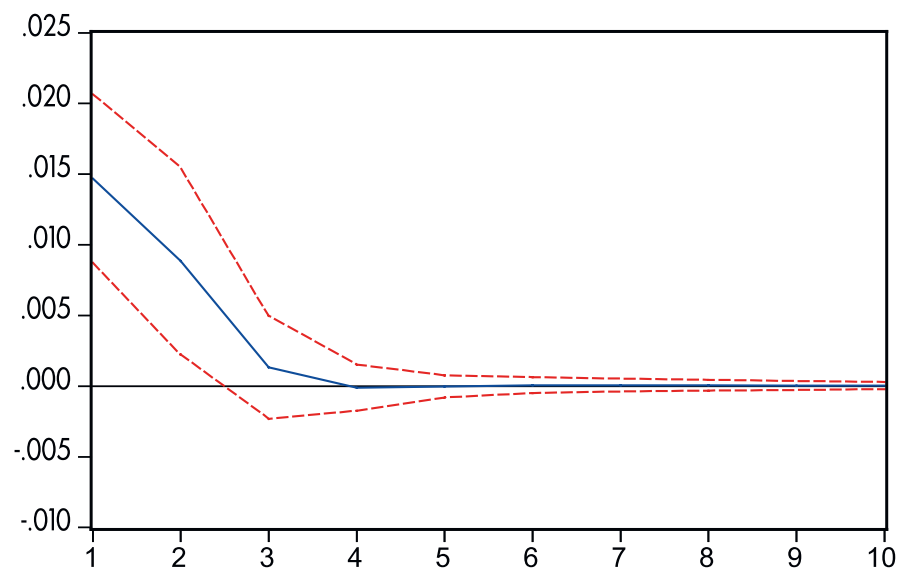

Response of DELTA_CAMBIO_NOMINAL to DELTA_DIFERENCIAL_JUROS

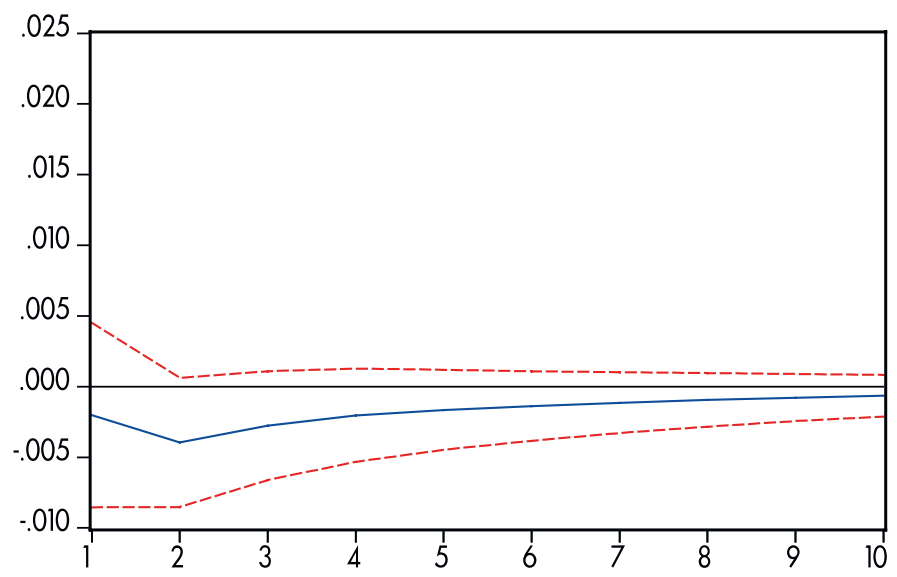

Fonte: Elaboração própria a partir do software e-views 6.0. 
Intuitivamente, entende-se que um aumento no diferencial de juros (por exemplo, um aumento nos juros domésticos mantendo os juros internacionais constantes) tende a apreciar a moeda nacional (queda na taxa de câmbio R $\$ /$ US\$), uma vez que há imediatamente um aumento na oferta de dólares, via atração de capitais estrangeiros de curto-prazo para os títulos domésticos.

Após a avaliação das respostas da taxa de câmbio a impulsos próprios e nas demais variáveis, cabe a análise da decomposição da variância. A decomposição da variância é considerada uma ferramenta útil de análise, uma vez que mostra a evolução do comportamento dinâmico apresentado pelas variáveis em questão, desde o primeiro até o n-ésimo período à frente.

A análise da decomposição da variância, conforme a Tabela 6, mostra que as variações na taxa de câmbio nominal são fortemente determinadas pela própria taxa de câmbio do período anterior. No primeiro período, cerca de $66 \%$ da variação do câmbio é explicada pelo próprio câmbio. Essa participação se reduz gradativamente, até atingir cerca de $57 \%$ no décimo período após o choque. Isso pode ser interpretando, conforme avaliado na resposta ao impulso, como sendo o papel da própria variação cambial sobre as expectativas dos agentes, que naturalmente tende a se dissipar com o passar do tempo. Observa-se também a forte presença do risco-país explicando as variações da taxa de câmbio nominal. Nesse sentido, o risco-país no primeiro período explica cerca de 33\% das variações na taxa de câmbio. Essa variável aumenta sua participação na explicação das variações cambiais, e responde por cerca de 38\% das mesmas no décimo período.

A variação no diferencial de juros também influencia as variações na taxa de câmbio nominal, porém em grau bastante inferior às duas variáveis anteriores. É importante salientar, no entanto, que a participação dessa variável na explicação das variações cambiais é a que mais cresce proporcionalmente até o décimo período. De fato, no primeiro período, a variação no diferencial de juros explica apenas $0,62 \%$ da variação cambial, sendo que no décimo período a participação aumenta para cerca de $5 \%$. Portanto, a influência da variação no diferencial de juros sobre o câmbio tem um impacto menor no curto-prazo, mas tal impacto tende gradualmente a crescer com o passar do tempo.

Esse resultado mostra, como será discutido mais detalhadamente adiante, que a política monetária, isto é, a determinação da meta para a taxa de juros básica da economia pelo Banco Central, tem efeitos diretos sobre a taxa de câmbio nominal. Entretanto, os fatores macroeconômicos mais amplos e a própria conjuntura externa, representados pelo risco-país, têm um impacto mais intenso sobre a taxa de câmbio, especialmente no curto prazo. 
Tabela 4 - Decomposição da variância (\%), câmbio nominal - Modelo UIP adaptado

\begin{tabular}{ccccc}
\hline Período & S.E. & $\begin{array}{c}\text { Delta_Cambio } \\
\text { Nominal }\end{array}$ & Delta_Risco & $\begin{array}{c}\text { Delta_Diferencial } \\
\text { Juros }\end{array}$ \\
\hline 1 & 0,02554409 & 66,3059 & 33,0670 & 0,62716 \\
2 & 0,027570811 & 58,6917 & 38,7099 & 2,5984 \\
3 & 0,027803988 & 58,1619 & 38,2935 & 3,5446 \\
4 & 0,027878674 & 57,8511 & 38,0901 & 4,0587 \\
5 & 0,027928659 & 57,6513 & 37,9540 & 4,3947 \\
6 & 0,027963076 & 57,5133 & 37,8612 & 4,6255 \\
7 & 0,027986654 & 57,4183 & 37,7980 & 4,7837 \\
8 & 0,028002757 & 57,3535 & 37,7549 & 4,8916 \\
9 & 0,028013755 & 57,3093 & 37,7255 & 4,9652 \\
10 & 0,02802127 & 57,2792 & 37,7054 & 5,0154 \\
\hline
\end{tabular}

Fonte: Elaboração própria a partir do software E-views 6.0.

\subsection{Avaliação dos Resultados}

Os testes realizados na seção anterior permitem a elaboração de uma avaliação a respeito do processo de formação da taxa de câmbio, especialmente para o caso brasileiro. A observação dos resultados dos testes econométricos, através da análise da função impulso-resposta e da decomposição da variância, mostra que a taxa de câmbio nominal no Brasil, no período de janeiro de 2003 a março de 2008 , apresentou como principais determinantes a própria variação cambial e a variação do risco-país.

Em linhas gerais, podemos pensar que a influência da taxa de câmbio sobre a sua própria variação pode ser entendida, em parte, como o papel das expectativas dos agentes sobre a taxa de câmbio. Conforme discutido no primeiro capítulo, as transações cambiais acontecem não somente para liquidar os pagamentos de bens e serviços, mas, em grande medida, devido às operações de hedge e especulação. A influência das expectativas nesse tipo de operação é extremamente relevante.

De fato, em geral, a expectativa para o valor futuro de uma variável depende fortemente do valor atual dessa variável, de modo que uma variação brusca no valor corrente de uma variável provavelmente afetará a expectativa de seu valor futuro. No processo de formação de expectativas conhecido como "expectativas adaptativas", os agentes utilizam os valores passados da variável como principal referência para a formação do valor futuro esperado. Assim, a hipótese de que a taxa de câmbio afeta a sua própria variação, via formação de expectativas, parece ser bastante plausível.

A outra variável importante que determina a variação cambial, segundo o resultado do estudo econométrico, é o prêmio de risco ou risco-país. Holland (2006), em um estudo que avalia a volatilidade da taxa de câmbio no Brasil e o medo de flutuar, cita o estudo de Calvo e Reinhart (2002), que utiliza um modelo 
simples para descrever porque um país supostamente poderia preferir taxas de câmbio que variam suavemente. O modelo parte da hipótese de que a variância das taxas de câmbio são independentes da variância do prêmio de risco, ou em suas próprias palavras, "[...] variance of the exchange rates are independent of the variance of the risk premium".

Holland (2006) destaca, no entanto, que, para o caso brasileiro, a variância do prêmio de risco parece ser uma das principais fontes de volatilidade da taxa de câmbio. Na mesma linha, o resultado do estudo econométrico apresentado neste trabalho demonstra que, para o caso brasileiro, no período considerado, a variação do risco-país é uma variável extremamente relevante para explicar as variações cambiais.

É fato que o Brasil atualmente é considerado um país emergente, isto é, um país que está em fase de crescimento, cuja economia ainda não atingiu sua plena maturidade. Em função dessa posição no cenário mundial, os investidores internacionais ainda olham as oportunidades de investimento no Brasil, tanto direto quanto em carteira, com bastante cuidado, apesar de reconhecerem que o potencial de retorno desses investimentos pode ser bastante alto.

Como consequência, a medida do risco-Brasil é extremamente relevante para os investidores internacionais como um importante balizador para as decisões de investimento, em especial para os investimentos de curto e médio prazo em títulos brasileiros. Assim, variações na medida do risco-país podem afetar a taxa de câmbio brasileira, principalmente em função desse tipo de operação.

Neste ponto cabe uma discussão a respeito de como a medida do risco-país é formada e qual o seu significado mais amplo em termos econômicos. Antes disso, contudo, é importante salientar que não existe uma medida única e consensual que represente a percepção do risco em se investir em um determinado país.

Em termos práticos, no entanto, as agências especializadas em classificação de risco divulgam índices que procuram avaliar o risco de se investir em um determinado país. De uma forma ampla, esses índices procuram medir a capacidade e a "vontade" dos países de honrarem seus compromissos, isto é, o pagamento dos juros e principal das dívidas assumidas.

Em relação à capacidade de honrar seus compromissos, temos como principais determinantes variáveis macroeconômicas, como a taxa de crescimento do PIB, a taxa de inflação, a relação dívida pública/PIB, e o saldo da balança comercial, entre outras, e a condução da política econômica pela autoridade monetária. Quanto à "vontade" de honrar seus compromissos, a análise é mais subjetiva e diretamente ligada a questões políticas e ideológicas, bem como à estabilidade do regime e à qualidade das instituições.

Dentre as medidas do risco de se investir no Brasil, destaca-se a realizada pelo JP Morgan, denominada EMBI+ Brazil. Conforme discutido na seção 5.3, o 
$\mathrm{EMBI}+$ Brazil é um índice que representa o spread entre o retorno de uma carteira de instrumentos da dívida externa brasileira e o retorno dos títulos do tesouro norte-americano. Assim, o índice do risco-país depende, não apenas da situação das principais variáveis macroeconômicas do país em questão, mas também fortemente da situação da economia dos Estados Unidos, uma vez que os títulos do tesouro desse país são a referência para a formação do índice.

Dessa forma, verificamos que o risco-país capta, de maneira abrangente, a situação da economia brasileira em termos macroeconômicos, bem como a situação da economia central, representada pelos Estados Unidos da América. Por ser formado com base em uma série de indicadores macroeconômicos, incluindo aqueles que formam os denominados "fundamentos" da economia, o risco-país pode ser interpretado como uma medida que reflete amplamente a situação da economia do país.

Conforme avaliado no estudo econométrico apresentado, essa medida abrangente da situação da economia do país pode ser considerada a principal determinante das variações cambiais no Brasil. Com base nesse resultado, é interessante avaliarmos o desdobramento qualitativo dos determinantes das variações cambiais no Brasil, quais sejam: a situação do ambiente externo, especialmente da economia norte-americana, a situação das contas externas brasileiras, com destaque para a balança comercial e o comportamento das principais variáveis macroeconômicas domésticas, como a taxa de crescimento do PIB, a taxa de inflação e a relação entre a dívida pública e o PIB.

O estudo econométrico mostrou, ainda, que a condução da política monetária pelo Banco Central do Brasil, considerando-se principalmente a determinação da taxa de juros básica da economia, é uma variável que também participa do processo de formação da taxa de câmbio. Em comparação com a própria variação cambial e com o risco-país, no entanto, a relevância do diferencial de juros é consideravelmente menor.

Apesar disso, a importância do diferencial de juros como fator explicativo das variações cambiais apresentou uma tendência de crescimento ao longo do tempo, resultado demonstrado pela decomposição da variância. Dessa forma, o estudo indica que a política monetária não tem um efeito tão intenso sobre as variações cambiais quanto as variáveis que determinam o risco-país, mas que, apesar disso, os efeitos de variações nas taxas de juros tendem a ter uma duração superior aos choques no risco-país.

Os resultados, portanto, vão ao encontro da ideia de que a apreciação da moeda brasileira, desde o início de 2003, foi fortemente determinada pelas condições da economia internacional, em especial pela perda de prestígio do dólar estadunidense e pela melhoria nas condições das contas externas brasileiras, principalmente em relação à balança comercial, pelo controle da inflação doméstica e pela redução substancial da parcela da dívida pública atrelada ao câmbio. 
A política monetária certamente teve efeito sobre as variações cambiais, no entanto, segundo os resultados dos testes, esse efeito teve menor participação na explicação do câmbio, especialmente no curto prazo.

\section{Considerações Finais}

O presente trabalho procurou apresentar um estudo a respeito da taxa de câmbio. O objetivo principal do estudo empírico foi entender mais claramente quais são os principais fatores determinantes das variações cambiais no Brasil, no regime de câmbio flutuante, e qual o peso de cada um deles no processo. $\mathrm{O}$ modelo econométrico baseou-se na paridade descoberta da taxa de juros (UIP), em uma adaptação que apresenta a vantagem de não exigir a elaboração de inferências a respeito da taxa de câmbio esperada no futuro.

Os resultados do estudo mostraram que a variação da taxa de câmbio no Brasil, no período de janeiro de 2003 a março de 2008, foi mais influenciada pelas próprias variações cambiais e pelo risco-país. O diferencial entre os juros domésticos e internacionais apareceu como uma variável menos relevante para explicar as variações cambiais, porém o efeito de choques sobre essa variável apresentou duração mais longa que os choques sobre o risco-país e sobre o próprio câmbio.

Assim, o resultado do teste mostrou que a influência direta da política monetária sobre o câmbio foi inferior à influência da variação no risco-país. Esse é um resultado importante para os debates sobre a relação entre as variáveis câmbio/ juros no Brasil. Ao menos para o período analisado e de acordo com a metodologia econométrica utilizada, a taxa de juros teve um papel menos relevante na determinação do comportamento da taxa de câmbio do que aquele esperado, entre outros, por Bresser-Pereira (2007). Os resultados obtidos neste trabalho sugerem que o autor exagerou no peso dado à taxa de juros enquanto determinante do comportamento do câmbio para o período analisado.

É importante lembrar que a medida do risco-país leva em consideração um conjunto de informações que reflete a situação da economia internacional (principalmente da economia norte-americana), das contas externas (notadamente da balança comercial) e das variáveis macroeconômicas domésticas (como a taxa de inflação, a taxa de crescimento do PIB e a relação dívida pública/PIB). A economia brasileira ainda ocupa uma posição de país emergente no cenário internacional, o que torna o investimento estrangeiro, uma parte substancial das operações cambiais, extremamente suscetível às classificações de risco realizadas pelas agências.

O fato de a variação cambial defasada aparecer como um importante determinante das variações cambiais reflete possivelmente a importância dos valores passados da variável na formação das expectativas para os valores futuros da 
mesma. As transações cambiais acontecem não somente para liquidar os pagamentos de bens e serviços, mas, em grande medida, devido às operações de hedge e à especulação. A influência das expectativas nesse tipo de operação é extremamente relevante.

Em síntese, o resultado da análise empírica sugere que a variação da taxa de câmbio no Brasil está intimamente ligada às condições da economia internacional e à situação das variáveis macroeconômicas que modificam o posicionamento do Brasil no cenário mundial. Por outro lado, os resultados encontrados relativizam os efeitos da política monetária doméstica sobre o câmbio no período analisado.

\section{Referências}

BANCO CENTRAL DO BRASIL - Bacen. Country Risk. Brasília: BACEN, 1995. (Frequently Asked Questions Series).

BOGDANSKI, J.; TOMBINI, A.; WERLANG, S. Implementing Inflation Targeting in Brazil. Working Papers of Central Bank of Brazil, Brasília, n.1, p. 1-29, Jul. 2000

BRESSER-PEREIRA, L. C. Macroeconomia da estagnação: crítica da ortodoxia convencional no Brasil pós-1994. São Paulo: Editora 34, 2007.

CALVO, G.; REINHART, C. Fear of floating. NBER Working Paper Series, Cambridge, n. 7993. Nov. 2000.

DOOLEY, M. P. D.; ISARD, P. The portfolio-balance model of exchange rates. International Finance Discussion Papers, Washington, US, n. 141, May 1979.

DORNBUSCH, R. Expectations and Exchange Rate Dynamics. The Journal of Political Economy, Chicago, US, v. 84, n. 6, p. 1161-1176, Dec. 1976.

DORNBUSCH, R.; FISHER, S. Exchange rates and the current account. American Economic Review, Nashville, US, v. 70, n. 5, p. 960-971, Dec. 1980.

EDWARDS, S. The Relationship Between Exchange Rates and Inflation Targeting Revisited. NBER Working Paper, n. 12163, Apr. 2006

EICHENGREEN, B. Global Imbalances and the Lessons of Bretton Woods. NBER Working Paper, Cambridge, US, n. 10497, May 2004.

ENGLE, R. F.; GRANGER, C. W. J. Co-integration and error correction: representation, estimation and testing. Econometrica, Chicago,US, v. 55, n. 2, p. 251-276, Mar. 1987.

ENDERS, W. Applied Econometric Time Series. 2nd ed. Hoboken: Wiley, 2006.

FISHER, I. Theory of interest. New York: McMillan, 1930.

FRANKEL, J. On the Mark: A Theory of Floating Exchange Rates Based on Real Interest Differentials. The American Economic Review, Nashville, US, v. 64, p. 610-622, Sep. 1979.

GRANGER, C.W.J.; NEWBOLD, P. Spurious regressions in econometrics. Journal of Econometrics, Amsterdam, NL, v. 2, p. 111-120, 1974.

HOOPER P.; MORTON, J. Fluctuations in the dollar: A model of nominal and real exchange rate determination. Journal of International Money and Finance, Amsterdam, NL, v.1, p. 39$56,1982$. 
HOLLAND, M. Exchange Rate Volatility and the Fear of Floating in Brazil. Revista Economia, Brasília, v. 7, n. 2, p. 279-292, May/Aug. 2006.

KEYNES, J. M. A Tract to Monetary Reform. London: MacMillan, 1923.

MUINHOS, M. K.; FREITAS, P. S.; ARAÚJO, F. Uncovered Interest Parity with Fundamentals: a Brazilian Exchange Rate Forecast Model. Working Series Papers, Brasília, n. 19, p. 1-28, Aug. 2001.

OBSTFELD, M.; ROGOFF. K. Foundations of International Macroeconomics. Cambridge: MIT Press, 1996.

Recebido em: 05/11/2010. Aceito em: 26/08/2012. 